\title{
Influence of Grain Size and Feed Rate on Selected Aspects of Corundum Ceramic Grinding Using Spherical Diamond Heads
}

\author{
Artur Szajna ${ }^{1 *}$, Anna Bazan' \\ 1 Department of Manufacturing Techniques and Automation, Rzeszow University of Technology, Al. Powstańców \\ Warszawy 8, 35-959 Rzeszów, Poland \\ * Corresponding author's e-mail: a.szajna@prz.edu.pl
}

\begin{abstract}
The article presents the results of experimental research on the grinding of corundum ceramics in the pre-sintered state, with spherical diamond heads. The aim of the experiment was to determine the effect of grain size and feed rate on selected aspects of the grinding process of corundum ceramics with the use of spherical diamond heads. In the experiment, grinding wheels with a ball diameter of $3 \mathrm{~mm}$ and different grain sizes were used; the grain numbers were D64, D91, D126 and D181. The tests were carried out on the Ultrasonic 20 Linear machining center at a constant rotational rate of the grinding wheel $n=38,000 \mathrm{rpm}$ and a grinding depth of $30 \mu \mathrm{m}$. The feed rate was set on 3 values: 200, 400 and $600 \mathrm{~mm} / \mathrm{min}$. During the research, the process temperature was recorded with a thermal imaging camera. The topography of grinding wheels before and after the grinding process and the topography of the ground surface were also measured. The parameters $S a$ and $\hat{S z}(\hat{\mathrm{S} z}=\mathrm{Spk}+\mathrm{Sk}+\mathrm{Svk})$ were used to characterize the grinding heads. The conducted analyses showed the dependence of the parameters $S a$ and $\hat{S z}$ of new grinding heads on the grain size described by the quadratic function $\left(R^{2} \geq 0.94\right)$. Statistically significant changes in the parameters $S a$ and $\hat{S z}$ on the cutting surface of the grinding wheel, which occurred as a result of its wear, were observed. There was no significant relationship between the feed rate and the wear of grinding heads, probably due to the relatively small volume of the material removed. A positive correlation between the $S a$ and $\hat{S} z$ parameters of the ground object and the grain size was observed. The research also showed an increase in the process temperature with an increase in the feed rate and an increase in the grain size.
\end{abstract}

Keywords: grinding, corundum ceramic, spherical diamond head, grinding-wheel wear.

\section{INTRODUCTION}

Modern advanced materials, some of which are various types of ceramics, including corundum and zirconium ceramics, belong to the group of difficult-to-machine materials that cause problems when shaping the surface. Ceramic materials are widely used in the aviation, automotive and energy industries as well as in medical engineering as materials for bone and dental implants. Their specific properties, such as high hardness and high brittleness, mean that sometimes the only way to shape elements made of ceramics is grinding with diamond grinding Hades. Therefore, grinding is considered to be the basic method of finishing type of machining for ceramic products [1-4].
The authors of the studies [5-6] emphasize the influence of the grinding process on the surface quality of ceramic products. They consider the surface roughness parameters to be an important factor in the analysis of the surface quality after grinding ceramic elements.

Machining of geometrically complex surfaces made of materials such as ceramics is possible thanks to the use of spherical grinding heads and multi-axis CNC machines, which allow the tool to be tilted in two directions. Such kinematics of machines in combination with a high-speed spindle allows for any surface shaping of parts made of this type of materials [7-9].

The authors of the article [10] conducted a study of the influence of the lead angle and the tilt 
angle of the spherical diamond head on selected parameters of the machined surface topography. They determined for which tool setting angles a lower surface roughness value can be obtained. They also determined the influence of the tool orientation on the grinding force values. The authors also showed a relationship between the 5 -axis grinding and milling process in relation to the tool setting and the obtained force values.

In the article [11], the authors referred to the tool positioning angles in relation to the machined surface. The issues of the participation of the tool tip in the machining process and its influence on the machining surface were verified.

In publication [12], the authors presented the kinematics of 5-axis milling with a spherical mill. They described the orientation angles of the tool axis and determined their influence on the machining accuracy and surface quality. They also analyzed 3 -axis, $3+2$-axis and 5 -axis machining in terms of accuracy and parameters of the machined surface.

Articles [13-15] discuss the issues of grinding pre-sintered ceramics with spherical diamond heads. They raise issues related to the influence of technological parameters on surface quality. The works determined the dependence of grinding parameters on selected parameters of surface roughness. Another aspect described is the influence of the positioning of the tool axis on the machined surface. The authors also determined the correlations of the tool axis positioning angle values on the technological parameters of the grinding process.

In the articles $[16,17]$, the authors discussed the roughness parameters of ceramic materials after grinding. They developed models predicting the surface roughness, taking into account the topography of the grinding wheel, grain size and technological parameters of grinding. The authors of the publication [18] in their study showed the use of a thermal imaging camera to measure temperature in the grinding process. They demonstrated the usefulness of this solution for improving the temperature distribution models in the machining zone.

The publications $[19,20]$ describe the method of using a thermal imaging camera to measure the temperature of the machining zone. In both publications, the authors noted the advantages and disadvantages of this method of temperature measurement. The highlighted advantage of the method was the speed of obtaining results from a large area of the analyzed surface, and the disadvantage - the correct selection of the emissivity coefficients of the surface for which the measurement is performed.

Among the tools that enable the machining of elements made of ceramic materials, diamond heads play a significant role. As in finishing milling of complex surfaces, where a spherical mill is the first choice, the spherical heads are suitable for grinding this type of surface.

There are no studies describing the issues of grinding with spherical grinding heads in the scientific literature. The purpose of this paper is to present the relationship between the feed rate and its influence on tool wear, and the temperature of the machining zone and the condition of the machining surface after grinding corundum ceramics.

\section{MATERIALS AND METHODS}

The grinding tests were carried out on the Sauer Ultrasonic 20 Linear 5-axis machining center. Three Pferd DKU-A 3.0 / 3-42 spherical diamond heads with different grain sizes were used for the grinding process, as shown in Table

Table 1. Presentation of grinding heads used for tests

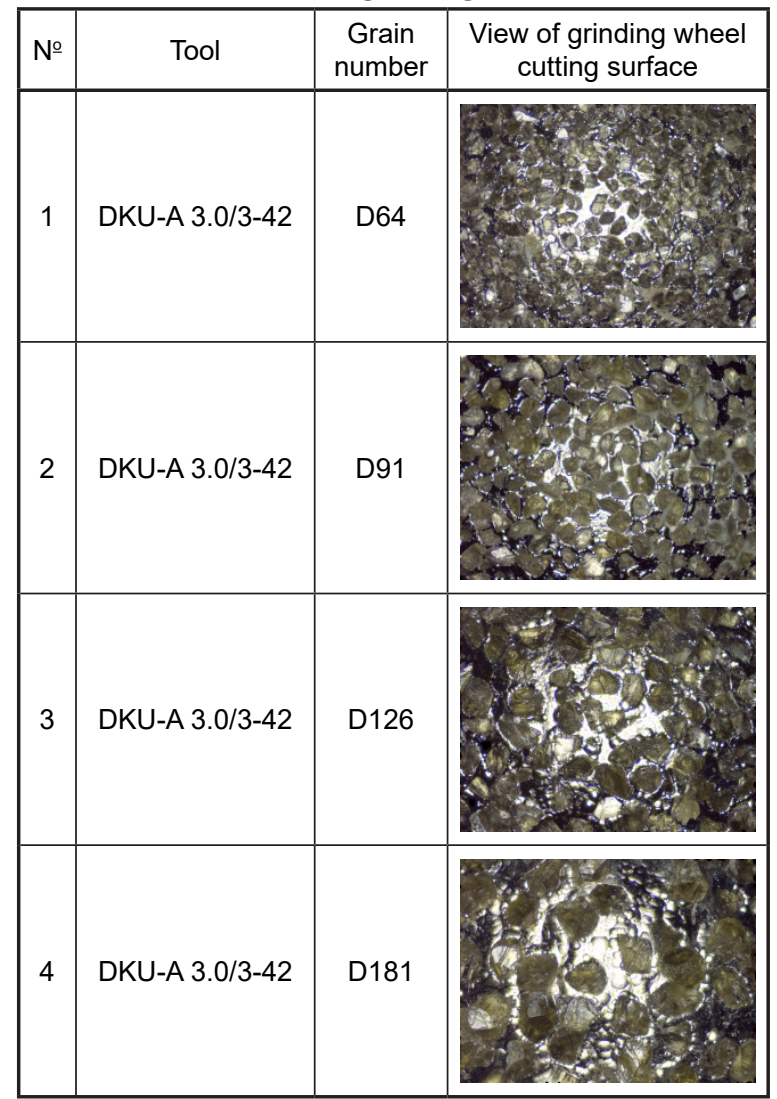


1. The tools were mounted in ER16 collet holders. The test object was attached to the machine table with a vice.

The machined material was pre-sintered corundum ceramics prepared in the form of two identical cubes with a side length of $40 \mathrm{~mm}$, divided into zones equal in terms of their surface area (Fig. 1).

During grinding, a single, constant angular position of the grinding head arbor in relation to the machined surface was assumed, described by the lead and tilt angles of $0^{\circ}$ and $35^{\circ}$, respectively. This is shown in Figure 2. The applied technological parameters during the grinding tests are shown in Table 2. The grinding width was determined in such a way as to maintain the scallop parameter at $1 \mu \mathrm{m}$.

The temperature in the machining zone was recorded during the grinding tests. For this purpose, a Flir SC5000 thermal imaging camera was used, placed on a tripod in such a way as to obtain the best possible view of the grinding zone. No coolant was used in the grinding tests. This was due to the process temperature recording method. The view of the test stand is shown in Figure 3.

The analysis of the grinding wheel topography before and after the grinding process was carried out on the 3D system InfiniteFocus - Alicona focus variation microscope, while the 3D TalyScan 150 profilometer was used to measure the topography of the ceramic surface after grinding.

Grinding wheel measurements were carried out with a $\times 10$ lens. Three areas $(1.04 \times 1.43 \mathrm{~mm})$ spaced $120^{\circ}$ apart were measured on each wheel. The same areas were measured before and after the grinding process. The topography of the grinding surface was measured by the contact

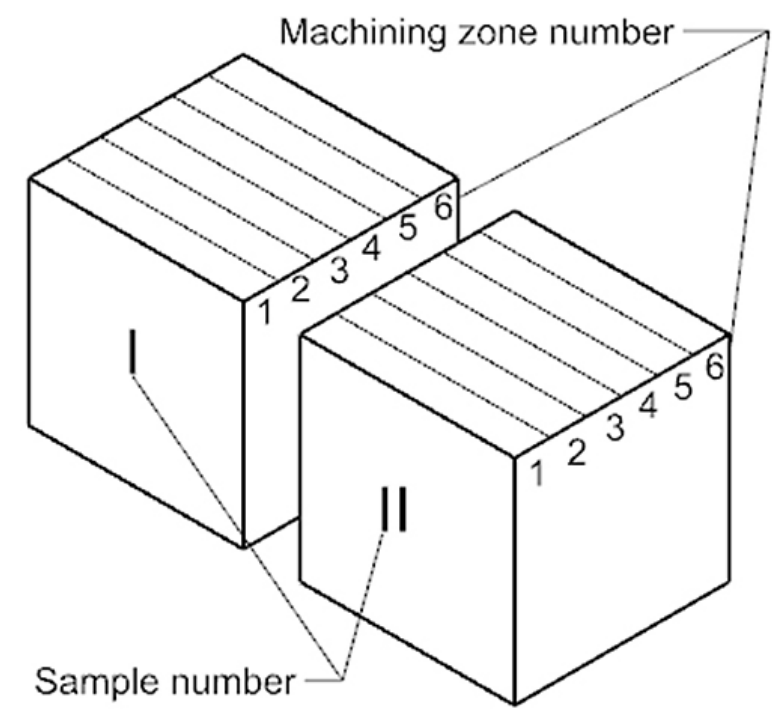

Fig. 1. Samples divided into machining zones

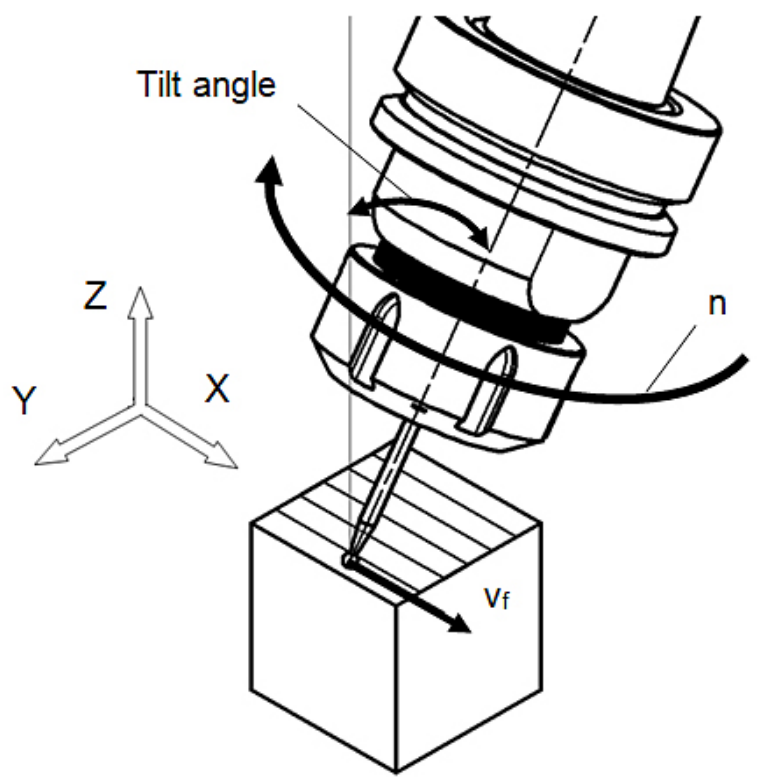

Fig. 2. Diagram showing the kinematics of the grinding tests performed

Table 2. Technological parameters used during machining

\begin{tabular}{|c|c|c|c|c|}
\hline № & Grain number & Average grain size $d_{g}[\mu \mathrm{m}]$ & Feed rate $v_{\mathrm{f}}[\mathrm{mm} / \mathrm{min}]$ & Other parameters \\
\hline 1 & D64 & 58 & 200 & \multirow{12}{*}{$\begin{array}{c}\text { Spindle speed } n=38000\left[\mathrm{~min}^{-1}\right] \\
\text { Grindind deapth } a_{p}=30[\mu \mathrm{m}] \\
\text { scallop parameter }=1[\mu \mathrm{m}]\end{array}$} \\
\hline 2 & D64 & 58 & 400 & \\
\hline 3 & $\mathrm{D} 64$ & 58 & 600 & \\
\hline 4 & D91 & 82.5 & 200 & \\
\hline 5 & D91 & 82.5 & 400 & \\
\hline 6 & D91 & 82.5 & 600 & \\
\hline 7 & D126 & 119.5 & 200 & \\
\hline 8 & D126 & 119.5 & 400 & \\
\hline 9 & D126 & 119.5 & 600 & \\
\hline 10 & D181 & 165 & 200 & \\
\hline 11 & D181 & 165 & 400 & \\
\hline 12 & D181 & 165 & 600 & \\
\hline
\end{tabular}




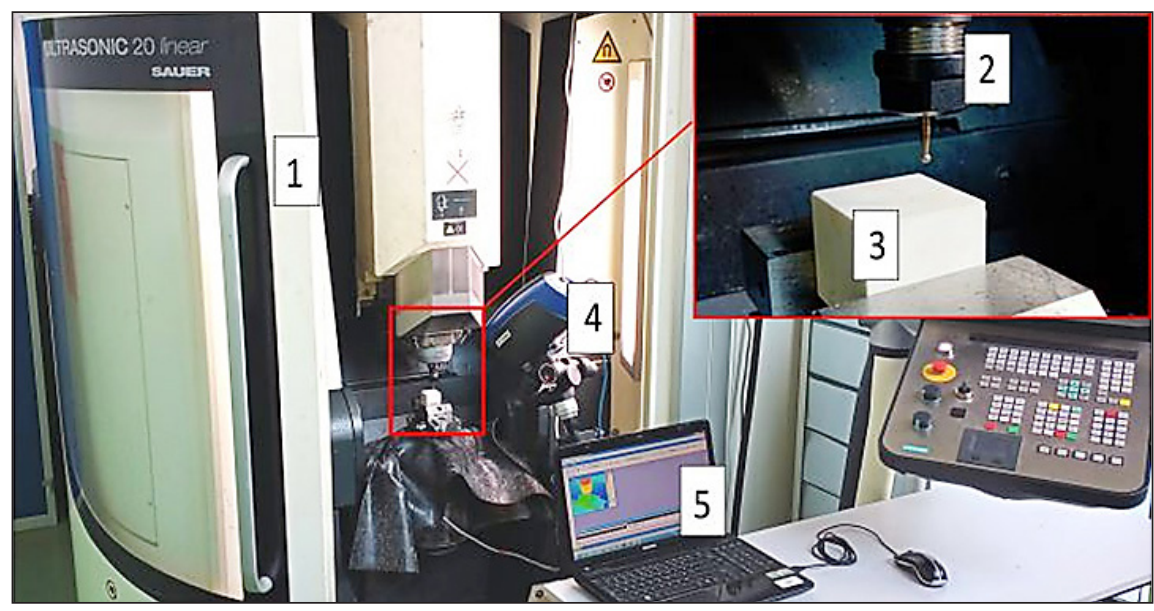

Fig. 3. View of the test stand: 1 - Ultrasonic 20 Linear machine tool, 2 - tool, 3 - workpiece, 4 - thermal imaging camera, 5 - computer

method with a sampling step in the horizontal axes of $5 \mu \mathrm{m}$. Five areas measuring $1 \times 1 \mathrm{~mm}$ were measured on each surface. The processing of the measurement data with the determination of 3D parameters of the geometric structure of the surface was carried out in the SPIP 6.4.2 program. Two hight parameters $S a$ and $\hat{S} z$ [15] were adopted for the analyses. In the case of the analysis of the topography of the active surfaces of the grinding wheels, due to the occurrence of atypical spikes and cavities that often accompany optical measurements, the directly determined $\mathrm{Sz}$ parameter was not taken into account. In order to limit the impact of the above-mentioned peaks, the value of $\mathrm{Sz}$ is approximated by the sum of the parameters of the material proportion curve:

$$
\hat{S z}=S p k+S k+S v k
$$

Statistical analyses were performed in the JMP 12 program. The significance level was set at 0.05 for all tests.

\section{RESULTS AND DISCUSSION}

\section{Topography of new grinding wheels}

Figures 4-7 presents exemplary topography maps of measured grinding wheel surfaces before and after grinding. The conducted analyses showed the dependence of the $S a$ parameters and the $\hat{S} z$ of new grinding wheels on the grain size $d_{g}$ described by the quadratic function (Fig. 5):

$$
\begin{aligned}
& S a=10.93-0.08 \cdot d_{g}+11.7 \cdot 10^{-4} \cdot d_{g}^{2} \\
& \hat{S}_{z}=26.69+0.27 \cdot d_{g}+23.2 \cdot 10^{-4} \cdot d_{g}{ }^{2}
\end{aligned}
$$

Analysis of variance showed the equations to be statistically significant $(p<0.0001)$. The coefficient of determination for the model with the variable $S a$ was $R^{2}=0.94$, and with the variable $\hat{S} z R^{2}=0.95$. The obtained results correspond to the linear relationship determined by Shi [22] linking the grain size $d_{g}$ with mean
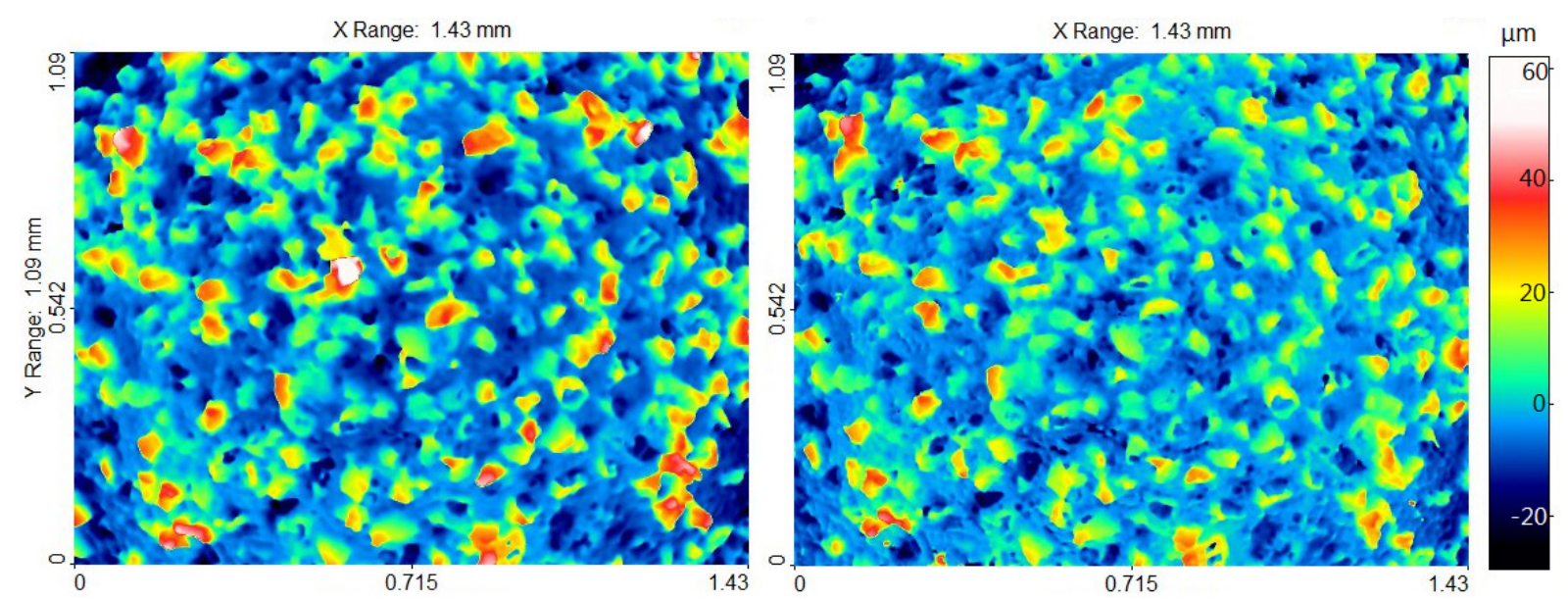

Fig. 4. Topography maps of new (left) and used (right) grinding wheel D64 

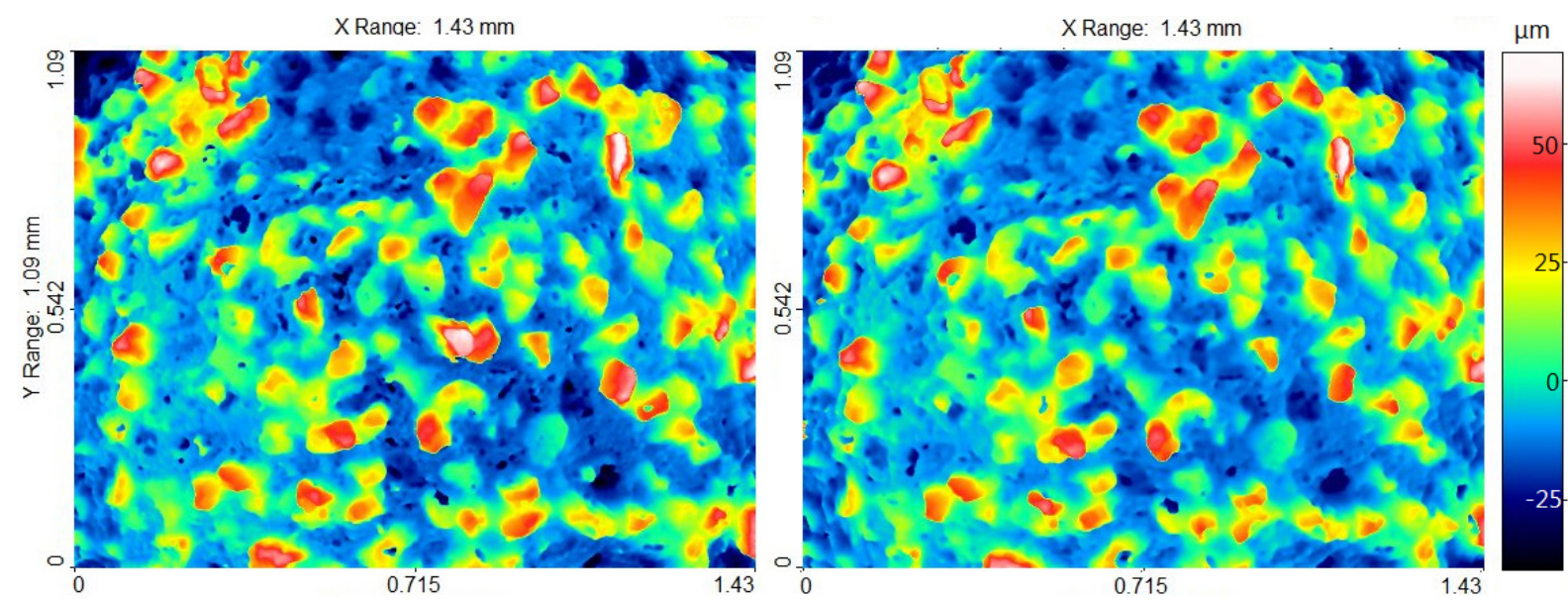

Fig. 5. Topography maps of new (left) and used (right) grinding wheel D91
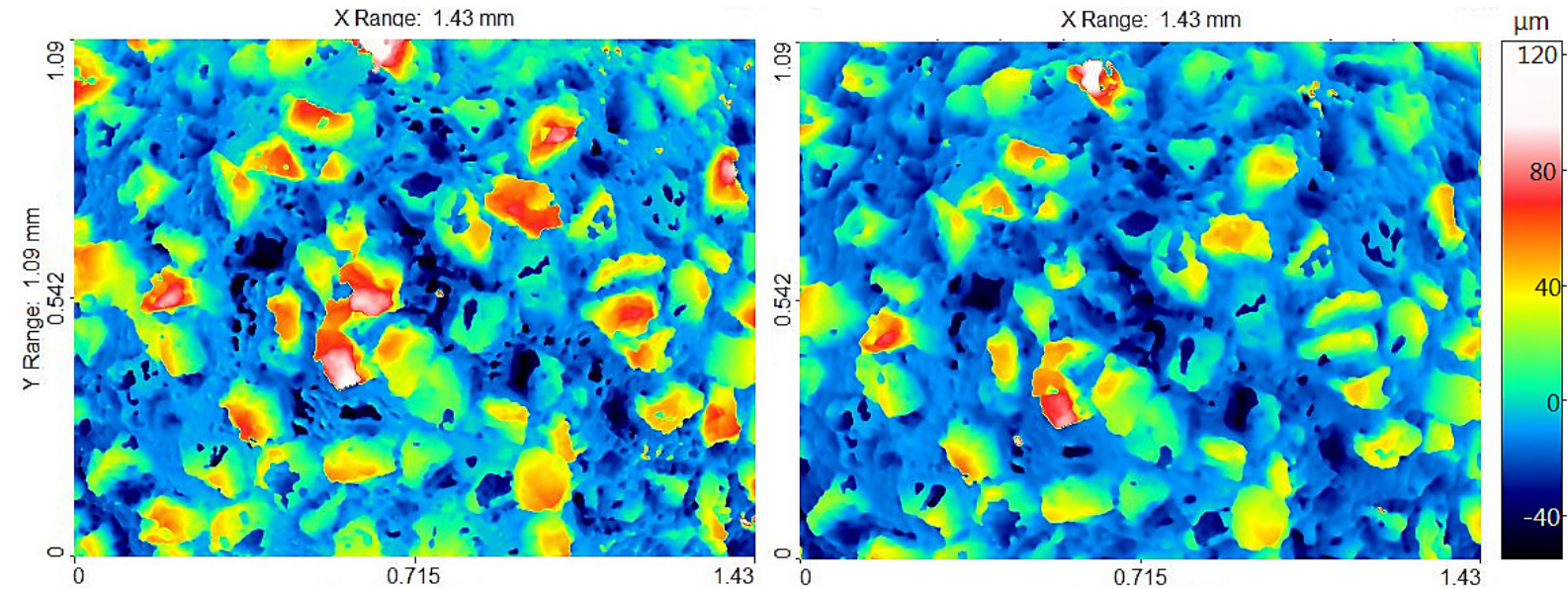

Fig. 6. Topography maps of new (left) and used (right) grinding wheel D126
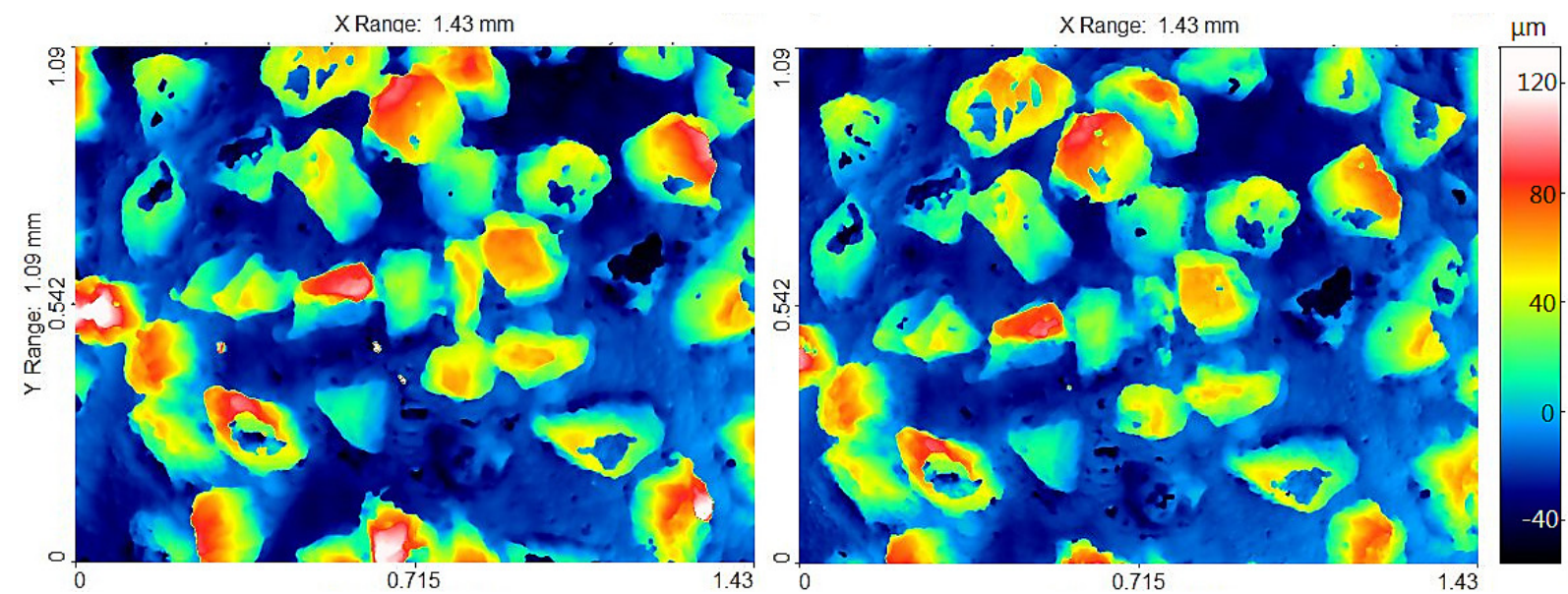

Fig. 7. Topography maps of new (left) and used (right) grinding wheel D181

grain protrusion heights. Determining the $S a$ or $\hat{S}_{z}$ from the measurement of the surface topography, however, is much simpler than the determination of grains protrusion heights.

In Figure 8 it is also visible that with the increase of the grain size the scatter of the results also increased. It was caused by the deterioration of the measurement conditions. The walls of the abrasive grains had very smooth surfaces, which in some places made it impossible to measure them correctly with the use of a focus variation microscope. 

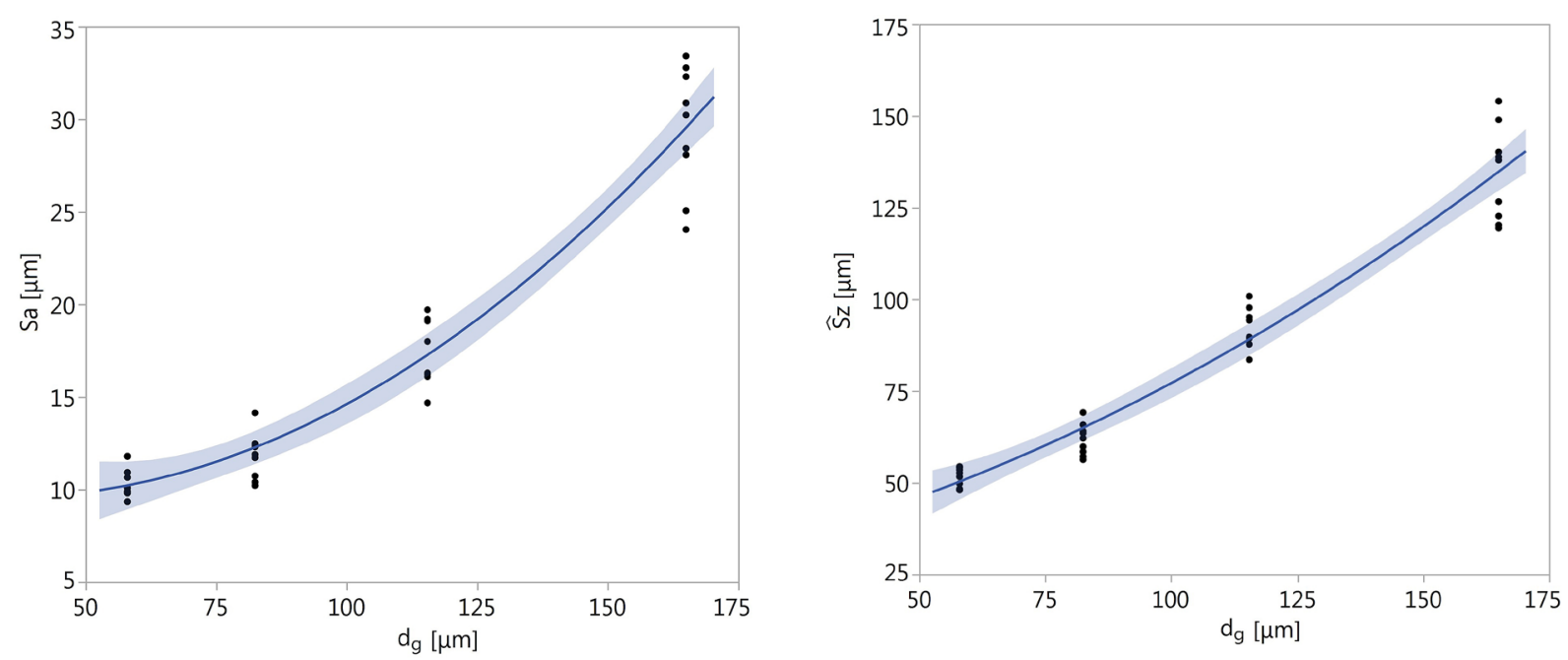

Fig. 8. Correlation of Sa i Ŝz parameters of new grinding wheels on grain size with a confidence interval of 0.95

\section{Influence of grain size on the wear of grinding wheel cutting surface}

When examining the wear of grinding wheels that occurred during the experiment, it was first checked whether the observed differences in the values of $S a$ and $\hat{S} z$ parameters of the active surfaces of new grinding wheels and those after the grinding process were statistically significant. For this purpose, Wilcoxon signed rank tests (earlier Levene's tests showed different variances in the studied groups) for each grain size separately were conducted. For all 4 tested cases, the tests showed that for the new grinding wheels, the values of $S a$ and $\hat{S} z$ parameters are statistically greater than for the used grinding wheels (Fig. 9).

The tests revealed the linear dependence of the parameters $S a$ and $\hat{S} z$ from the grinding head active surfaces after grinding on the parameter values characterizing the new grinding wheels (Fig. 10). Regression models take into account grinding wheels of all tested grain sizes and are expressed by the following formulas:

$$
\begin{aligned}
& S a(\text { used })=-0,04+0,93 S a(\text { new }) \\
& \hat{S} z(\text { used })=-1,48+0,97 \hat{S} z(\text { new })
\end{aligned}
$$

Analysis of variance showed the equations to be statistically significant $(p<0.0001)$. The coefficient of determination for the model with the variable $S a$ was $R^{2}=0.98$, and with the variable $\hat{S} z R^{2}=0.99$. The nature of the aforementioned model relationships with a very good fit indicates that the intensity of changes in the values of $S a$ and $\hat{S} z$ parameters was independent of the grain size. The publication [22] noted that the wear intensity of
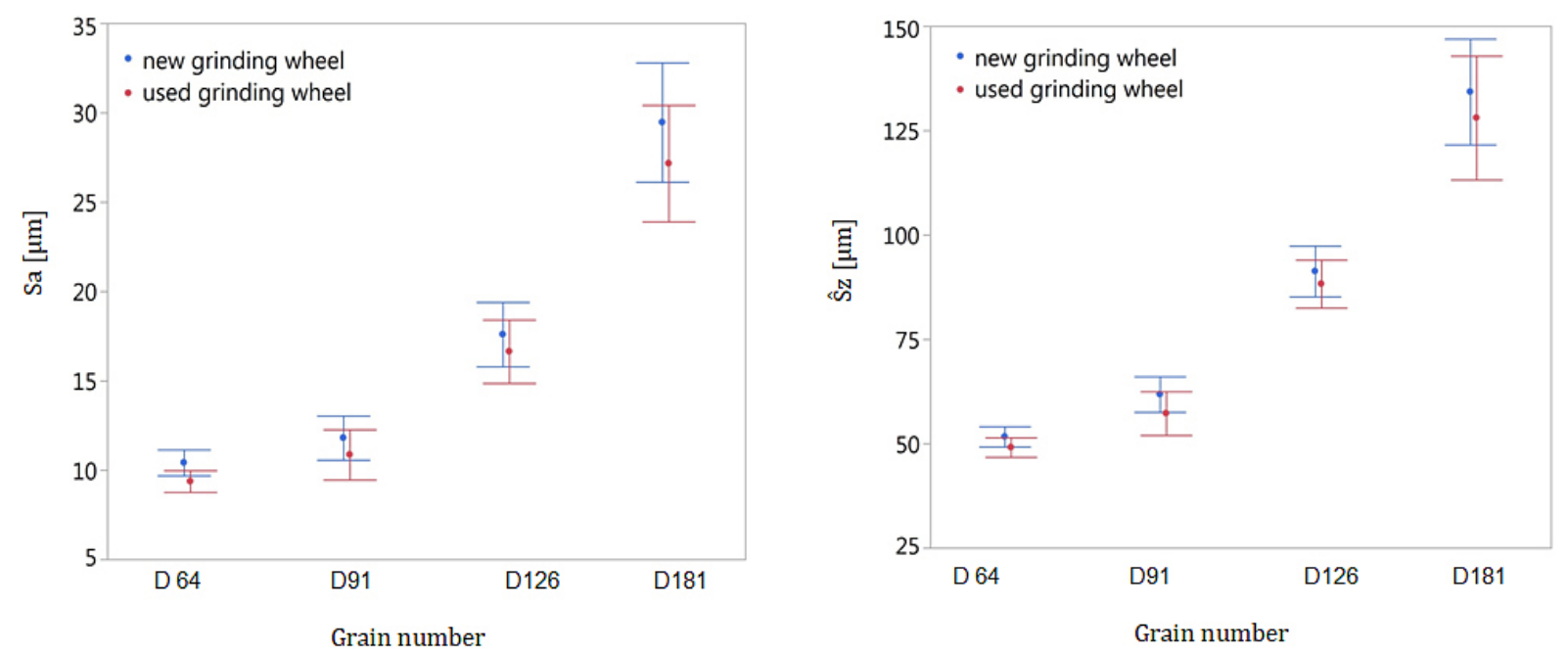

Fig. 9. Values of parameters $S a$ and $\hat{S} z$ before and after the grinding process 

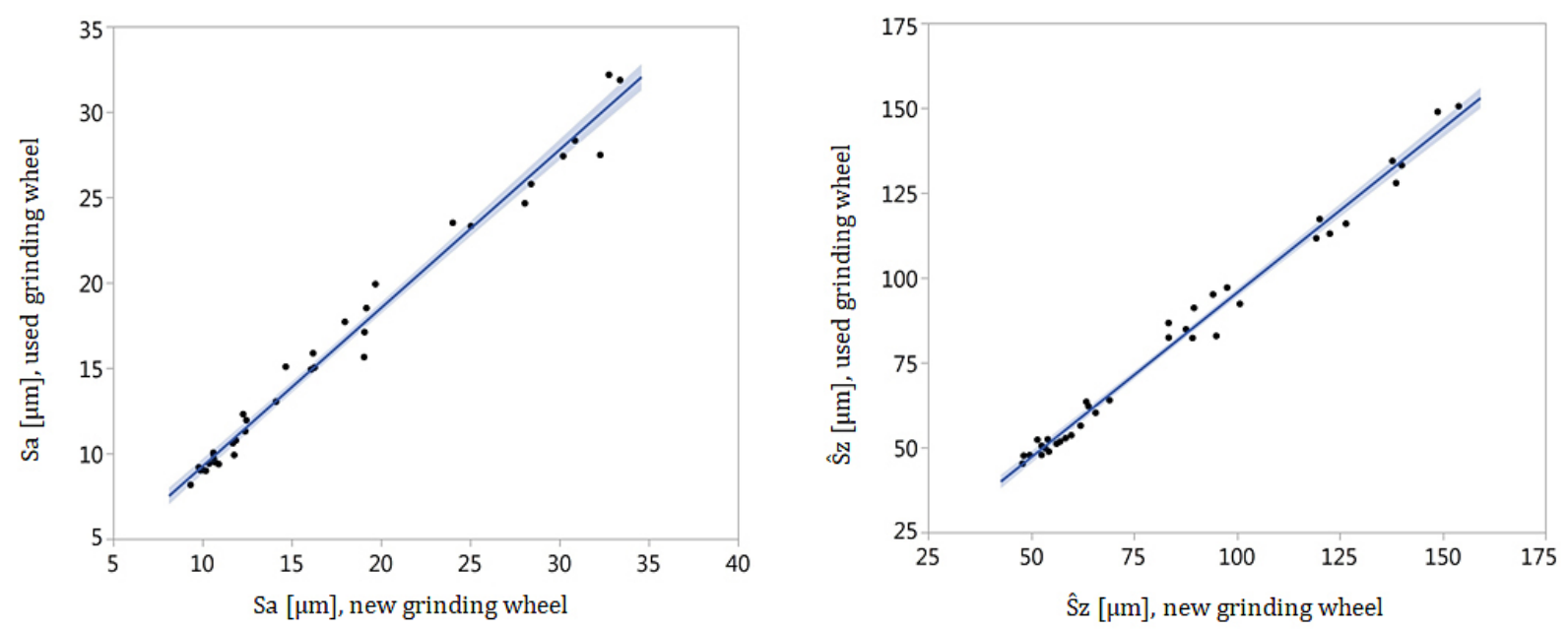

Fig. 10. Dependence of $S a$ and $\hat{S} z$ parameters of the grinding head active surfaces determined for used grinding wheels on the values of these parameters for new grinding wheels

grains $\mathrm{cBN}$ in the stable wear phase during steel grinding depends on their size. Taking into account the fact that in the conducted tests the grinding wheels showed relatively little material $\left(8 \mathrm{~mm}^{3}\right)$, it can be assumed that the observed wear resulted from the initial stage of wear of the abrasive grains, in which the grains are just lapping. In this phase, the wear is very intense. Afterwards occurs a phase of stable wear. Therefore, in order to verify the effect of grain size on the wear intensity, the research should be continued.

\section{Influence of feed rate on the wear of grinding wheel cutting surface}

With an increase in the feed rate, the grinding efficiency and the undeformed chip thickness, both being are a measure of the load on the grinding wheel - thus, the grinding force and power components also increase. This, in turn, is associated with increased wear of the grinding wheel [23, 24]. However, the analysis of variance did not show any significant dependencies between the feed rate and the wear of grinding wheels (observed through the parameters Sa and $\hat{\mathrm{S} z}$ from the active surface of the grinding wheel (Fig. 11) and their change).

Probably only in a phase of stable wear it would be possible to observe the influence of the feed on the different intensity of grain wear. Therefore, in order to verify the influence of the feed rate on the wear of grinding wheels, the research should be continued.
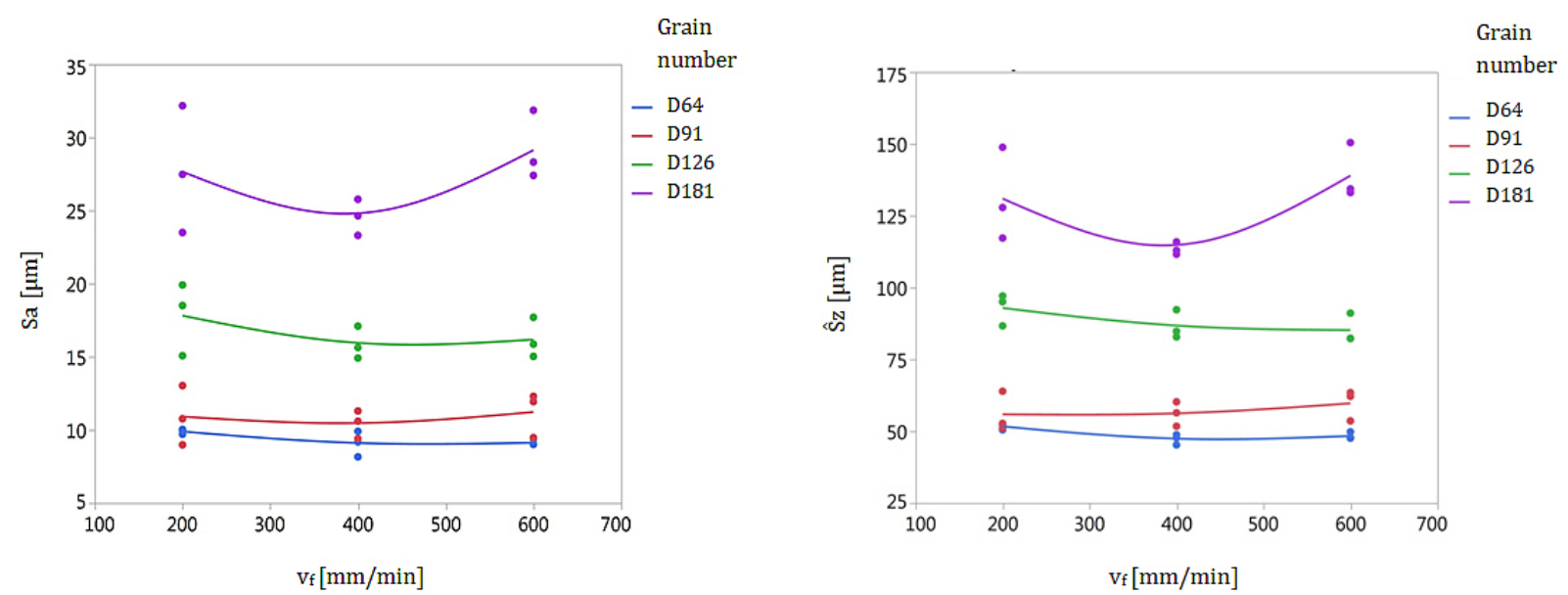

Fig. 11. Influence of the feed rate $v_{f}$ on the values of the parameters $S a$ and $\hat{S} z$ from the active surface of the grinding wheel after grinding (the lines are not regression lines, they were introduced for greater clarity) 
a) D64

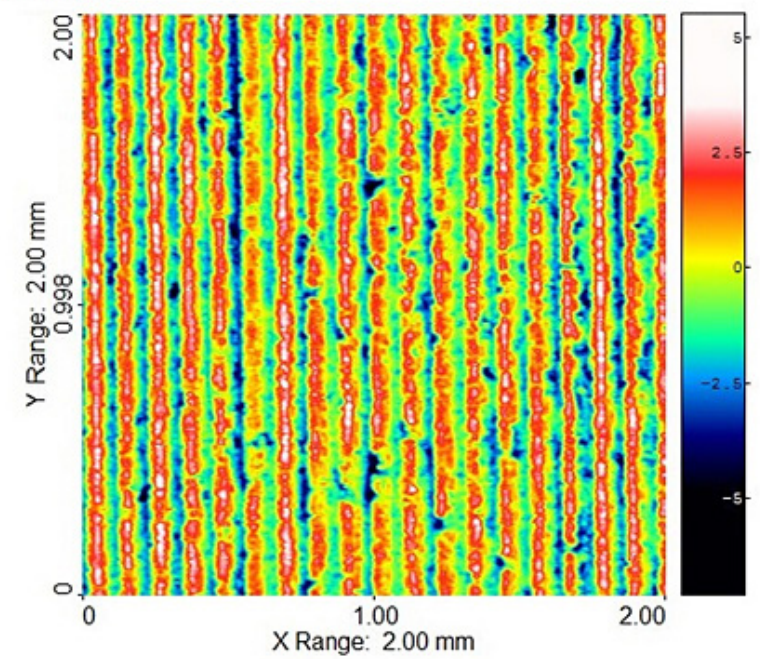

c) D126

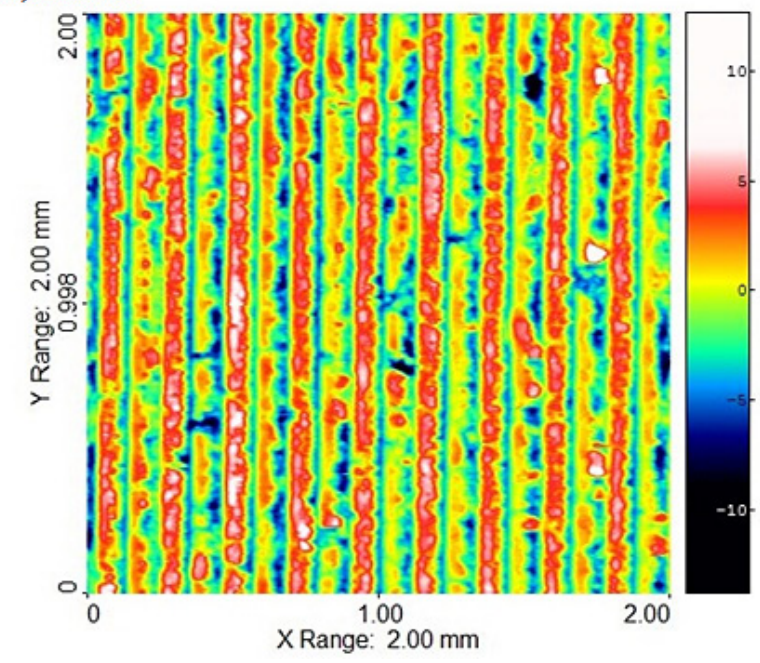

b) D91

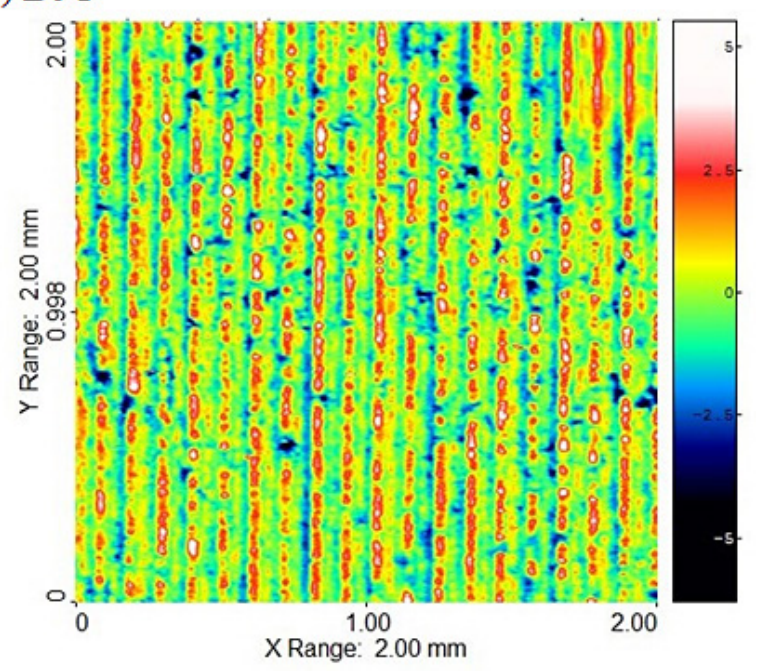

d) D181

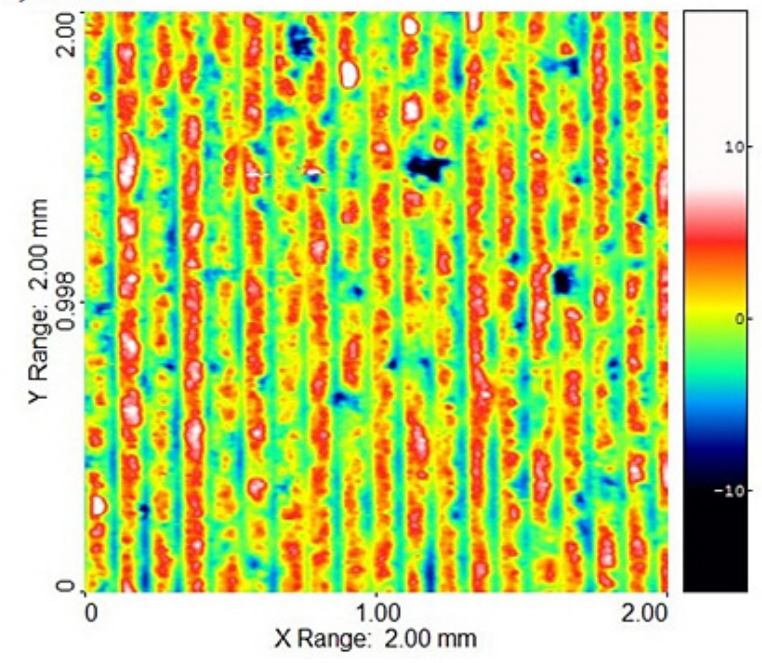

Fig. 12. Topography maps of surfaces ground with grinding wheels with different grain size

\section{Influence of grain size and feed rate on surface roughness}

Figures 12 presents exemplary topography maps of the ground surfaces. A positive correlation was observed between the grain size and the roughness parameter of the ground object Sa (Spearman's $\rho=0.73$ ) and Sz (Spearman's $\rho=0.68$ ) (Fig. 13). Smaller grain size is associated with the presence of a greater number of active grains on the grinding wheel, which favors machining the surface with lower roughness. Similar relationships for single-layer grinding wheels were reported in works [25-30].

In the conducted research it was not shown that the feed rate had a statistically significant influence on the tested parameters of the ground surface.

\section{Influence of grain size and feed rate on grinding zone temperature}

In the work, a regression analysis was carried out in order to investigate the effect of grain size and feed rate on the grinding temperature. For this purpose, the classical model of the response surface in the form of a second degree polynomial with two-factor interaction was used. In the determined model, the interaction of the feed rate and the grain size was not statistically significant. The developed model, with the adjusted coefficient of determiantion $R_{a d j}^{2}=0.97$, is expressed by the formula:

$$
\begin{gathered}
T=25+0.2 \cdot d_{g}+0.07 \cdot v_{f}-2 \cdot 10^{-3} . \\
\cdot\left(d_{g}-105.25\right)^{2}-9.7 \cdot 10^{-5} \cdot\left(v_{f}-400\right)^{2}
\end{gathered}
$$

Analysis of variance showed the equation to be statistically significant $(p<0.0001)$. The response area is graphically presented in Figure 14. 

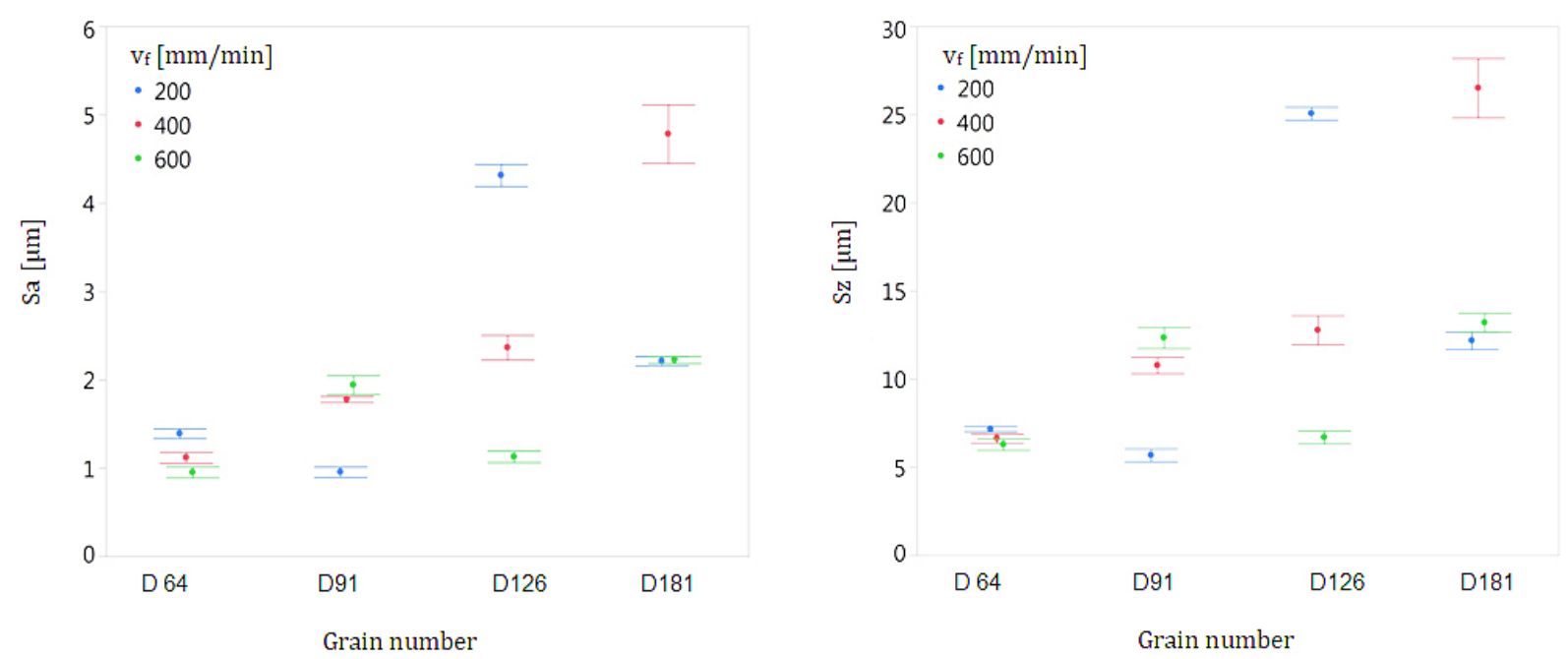

Fig. 13. Influence of grain size and feed rate $f$ on the values of parameters $S a$ and $S z$ from the ground surface

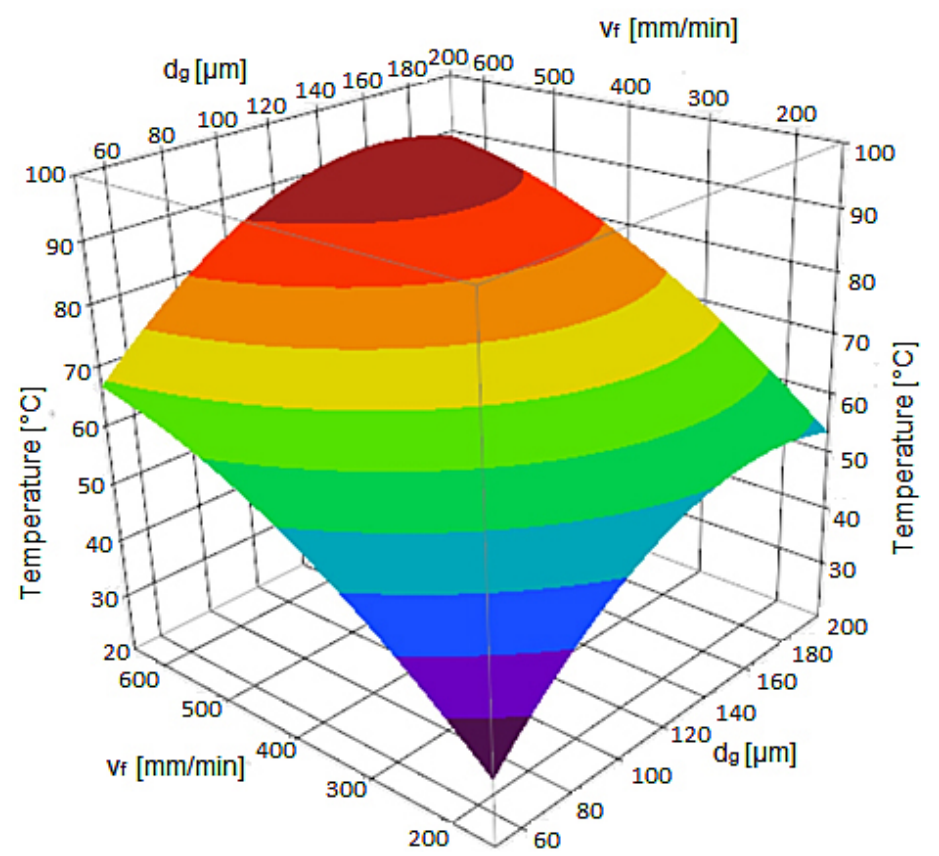

Fig. 14. Influence of grain size $d_{g}$ and feed rate $v_{f}$ on grinding temperature $T$

In the examined state space, the feed rate had a greater influence on the temperature than the grain size. The observed temperature values increased with the increase of the feed rate and the grain size. The tested factors had a greater impact on the temperature with their lower values.

Increasing the feed rate leads to an increase in the undeformed chip thickness and grinding power, and thus to an increase in the grinding temperature. For single-layer grinding wheels, this was confirmed, among others, by research [31, 32]. In the case of wheels with a smaller grain size on the grinding wheel, it can be expected that there were more active edges and the grains had a sharper shape, which reduced the undeformed chip thickness and grinding temperature [33-35].

\section{CONCLUSIONS}

The results of experimental tests presented in this study show that there is a relationship between the set feed rate and grain size and the wear of grinding wheels, surface quality and temperature in the treatment zone. For new grinding wheels, the relationship between the $S a$ and $\hat{S} z$ parameters on the grain size $d_{g}$ can be determined by the quadratic function. 
Increasing the grain size resulted in greater variability of the grinding wheel topography measurements, resulting from the limitations of the measurement method.

Examinations of the cutting surfaces of grinding wheels showed a linear relationship between $S a$ and $\hat{S} z$ parameters from worn to a new grinding wheel. The conducted analyses did not show any significant relations linking the feed rate and the wear of the grinding wheel. The reasons for this should be seen in the insufficient amount of material removed by each of the wheels used.

The analysis of the results revealed a positive correlation between the grain size and roughness parameters $S a$ and $\hat{S} z$. However, there is no clear influence of the feed rate $v_{f}$ on the discussed parameters of the roughness of the ground surface. The dependence of the grain size and the feed rate on the temperature in the grinding zone was observed. Both the increase in grain size and the increase in the feed rate resulted in an increase in temperature.

The presented study is a starting point for further research on the influence of technological parameters on the wear of spherical diamond heads and the surface condition of ceramic materials after grinding. The scope of research should be extended to increase the machining areas so that greater tool wear could be observed. Another aspect by which the scope of research can be extended are the variable positioning angles of the tool and their impact on the wear of the grinding wheel grains.

\section{Acknowledgements}

This work was financed from the funds of the Ministry of Education and Science by Agreement No. DNK/SP/513880/2021 of 22 December 2021, the project " $14^{\text {th }}$ School of Machining and the $43^{\text {rd }}$ Scientific School of Abrasive Machining", under the programme "Perfect Science".

\section{REFERENCES}

1. Schmidt Ch. Koordinatenschleifen dentalkeramischer Werkstoffe mit kleinen Diamantwerkzeugen. Shaker. 2008.

2. Alkhalefah H. Precise Drilling of Holes in Alumina Ceramic (A12O3) by Rotary Ultrasonic Drilling and its Parameter Optimization using MOGA-II. Materials. 2020;13(5):1059.
3. Cao J., Wu Y., Lu D., Fujimoto M., Nomura M. Fundamental machining characteristics of ultrasonic assisted internal grinding of SiC ceramics. Materials and Manufacturing Processes. 2014;29(5):557-563.

4. Ullah AMMS., Caggiano A., Kubo A., Chowdhury $\mathrm{M}$. Elucidating grinding mechanism by theoretical and Experimental Investigations. Materials. 2018;11(2):274.

5. Sanaei N., Fatemi A. Analysis of the effect of surface roughness on fatigue performance of powder bed fusion additive manufactured metals. Theoretical and Applied Fracture Mechanics. 2020;108:102638.

6. Panneer R., Harisubramanyabalaji S.P., Sribalaj C.A., Vivek A., Vigneshwaran G. Prediction of surface roughness using spectral analysis and image comparison of audio signals. International Journal of Precision Engineering and Manufacturing. 2016;17:709-715.

7. Borsoi Klein T. Prozessstrategien beim NC-formschleifen mit schleifstiften. Fraunhofer; 2015.

8. Uhlmann E., Borsoi Klein T., Hochschild L., Bäcker C. Influence of structuring by abrasive machining on the tribological properties of workpiece surfaces. Procedia Engineering. 2011;19:363-370.

9. Denkena B., Koehler J., Turger A., Helmecke P., Correa T., Hurschler C. Manufacturing conditioned wear of all-ceramic knee prostheses. Procedia CIRP. 2013;5:179-184.

10. Koprowski J., Uhlmann E., Weingaertner W. Influence of tilt and lead angles on 5-axis grinding with spherical mounted points. Production Engenering. 2018;12:449-455.

11. Ozturk E., Tunc T., Budak E. Investigation of lead and tilt angle effects In 5-axisball-end milling processes. International Journal of Machine Tools and Manufacture. 2009;49(14):1053-1062.

12. Sadílek M., Poruba Z., Cepová L., Šajgalík M. Increasing the Accuracy of Free-Form Surface Multiaxis Milling. Materials. 2021;14(1):25.

13. Burek J., Szajna A., Lisowicz J., Rydzak T. Surface accuracy and roughness parameters in free form grinding with the use of an spherical diamond head. Mechanik. 2017;90(8-9):763-765.

14. Burek J., Szajna A., Rydzak T. Influence of the tilt angle of an spherical diamond head for roughness parameters. Mechanik. 2018;91(8-9):706-708.

15. Burek J., Szajna A. Influence of the lead angle of an spherical diamond head on the roughness parameters of corundum ceramics. Mechanik. 2019;92(11)748-750.

16. Wu J., Cheng J., Gao Ch., Yu T., Guo Z. Research on predicting model of surface roughness in smallscale grinding of brittle materials considering grinding tool topography. International Journal of 
Mechanical Sciences. 2020;166:105263.

17. Kanakarajan P., Sundaram S., Kumaravel A., Rajasekard R., Venkatachalam R. Prediction of the surface roughness and wheel wear of modern ceramic material $\left(\mathrm{Al}_{2} \mathrm{O}_{3}\right)$ during grinding using multiple regression analysis model. Indian Journal of Engineering \& Materials Sciences. 2017;24:182-186.

18. Brosse A., Naisson P., Hamdi H., Bergheau J.M. Temperature measurement and heat flux characterizationin grinding using thermography. In: Proc. of 10th Advances in Materials and Processing Technologies: AMPT 2007, Daejeon, Korea, 2007, 1396-1405.

19. Grochalski K., Jabłoński P., Talar R., Twardowski P., Wieczorowski M., Jakubek B., Ruka W. Temperature Measurement of Modern Cutting Tools During Turning. Advances in Science and Technology Research Journal. 2020;14(4):37-48.

20. UrzędowskiA., Wójcicka-MigasiukD., Buraczyńska B. Visual Effects of Surface Emissivity in Thermal Imaging. Advances in Science and Technology Research Journal. 2020;14(2):215-222.

21. ISO 25178-2:2012. Geometrical product specifications (GPS) - Surface texture: Areal - Part 2: Terms, definitions and surface texture parameters.

22. Shi Z., Malkin S. Wear of Electroplated CBN Grinding Wheels. Journal of Manufacturing Science and Engineering. 2005;128(1):110-118.

23. Bazan A., Kawalec A., Rydzak T., Kubik P. Variation of Grain Height Characteristics of Electroplated cBN Grinding-Wheel Active Surfaces Associated with Their Wear. Metals. 2020;10(11):1479.

24. Tian Y.B., Zhong Z.W., Rawat R. Comparative study on grinding of thin walled and honeycombstructured components with two CBN wheels. The International Journal of Advanced Manufacturing Technology. 2015;81:1097-1108.

25. Soo S.L., Shyha I.S., Barnett T., Aspinwall D.K., Sim W.M. Grinding performance and workpiece integrity when superabrasive edge routing carbon fibre reinforced plastic (CFRP) composites. CIRP Annals - Manufacturing Technology. 2012;61:295-298.

26. Burrows J.M., Dewes R.C., Aspinwall D. K. Grinding of Inconel 718 and Udimet 720 Using Super- abrasive Grinding Points Mounted on a High Speed Machining Centre. In: Proc. of 33rd International MATADOR Conference: Formerly The International Machine Tool Desisgn and Research Conference, London, England. 2000;447-452.

27. Caggiano A., Teti R. CBN Grinding Performance Improvement in Aircraft Engine Components Manufacture. Procedia CIRP. 2013;9:109-114.

28. Chen J., Shen J., Huang H., Xu X. Grinding characteristics in high speed grinding of engineering ceramics with brazed diamond wheels. Journal of Materials Processing Technology. 2010;210(67):899-906.

29. Denkena B., Grove T., Lucas H. Influences of grinding with Toric $\mathrm{CBN}$ grinding tools on surface and subsurface of 1.3344 PM steel. Journal of Materials Processing Technology. 2016;210:541-548.

30. Hood R., Cooper P., Aspinwall D.K., Soo S.L., Lee D.S. Creep feed grinding of gamma-TiAl using single layer electroplated diamond superabrasive wheels. Journal of Manufacturing Science and Technology. 2015;11:36-44.

31. Vashista M., Kumar S., Ghosh A., Paul S. Surface Integrity in Grinding Medium Carbon Steel with Miniature Electroplated Monolayer cBN Wheel. Journal of Materials Engineering and Performance. 2010;19(9):1248-1255.

32. Zhao Z., Fu Y., Xu J., Zhang Z., Liu Z., He J. An investigation on high-efficiency profile grinding of directionalsolidified nickel-based superalloys DZ125 with electroplated CBN wheel. The International Journal of Advanced Manufacturing Technology. 2016;83(1):1-11.

33. Rowe W.B. Grinding technology-theory and applications of machining with abrasives. Tribology International. 1990;23(6):443.

34. Chakrabarti S., Paul S. Numerical modelling of surface topography in superabrasive grinding. The International Journal of Advanced Manufacturing Technology. 2008;39:29-38.

35. Zhu D., Li B., Ding H. An improved grinding temperature model considering grain geometry and distribution. The International Journal of Advanced Manufacturing Technology. 2013;67:1393-1406. 